Cómo citar este artículo en Chicago: Eiff, Leonardo Daniel. "Razones de una ausencia. Institución y política en MerleauPonty”. Escritos 28, no. 61 (2020): 18-30. doi: http://dx.doi.org/10.18566/escr.v28n61.a02

Fecha de recepción: 10.08 .2020

Fecha de aceptación: 14.09.2020

\title{
Razones de una ausencia. Institución y política en Merleau-Ponty
}

\author{
Reasons for an Absence: Institution and Politics in Merleau-Ponty
}

\author{
Leonardo Daniel Eiff'
}

\begin{abstract}
RESUMEN
El artículo parte de una perplejidad. Comienza advirtiendo una notable ausencia en el conocido curso merleaupontyano sobre La institución. En el curso no hay lugar para la institución de la política. A partir de ello, preguntamos: ¿por qué la política no merece un tratamiento específico a diferencia de la vida, la cultura, la historia? La respuesta nos lleva a indagar en las relaciones entre la filosofía de Merleau-Ponty y la política. El objetivo central del artículo es el siguiente: hallar un principio de explicación para el vínculo paradójico que establece Merleau-Ponty con la política en el curso sobre la institución: una intensa preocupación por las cuestiones políticas que no encuentra como correlato una reflexión teórica coherente. Para ello, en primer lugar, indagamos el vínculo con la filosofía de la historia de raigambre hegeliano-marxiana; en segundo lugar, identificamos un momento propiamente político ligado al nombre de Maquiavelo; en tercer lugar, destacamos las razones de la desvinculación entre la comprensión maquiaveliana de la política que alienta Merleau-Ponty y la novedosa perspectiva de la institución. Finalmente, nos preguntamos si esa desvinculación, que en el curso sobre la institución se convierte en ausencia, no puede ser indicación para escudriñar otra manera de pensar la política, ligada a las nuevas figuras conceptuales merleaupontyanas: vida, tiempo e institución. Las tres figuras fueron movilizadas por Merleau-Ponty para horadar el predominio de las filosofías de la conciencia son capaces de abrir nuevas hipótesis en torno a lo político y a la ligazón entre lo instituyente y lo instituido.
\end{abstract}

Palabras clave: Institución; Ausencia; Política; Historia; Revolución; Forma; Vida; Tiempo.

\begin{abstract}
The article derives from a perplexing situation. It brings a remarkable absence in the well-known lectures of Merleau-Ponty on Institution to attention: There is no mention of politics as an institution. Therefore, the article raises the following question: why the course does not deal with politics like it does with life, culture or history? To answer this question, the article addresses the relations between the philosophy of Merleau-Ponty and politics. Thus, the purpose of the article is to find the reason behind the contradictory link that Merleau-Ponty develops for politics in the lectures on Institution, that is, a profound concern over political issues that do not find theoretical considerations as complement. First, it considers the link with the philosophy of history of the Hegelian-Marxist
\end{abstract}

1 Doctor en Ciencias Sociales por la Facultad de Ciencias Sociales, Universidad de Buenos Aires, Argentina. Investigador Asistente (Conicet). Profesor de Teoría Política Moderna, Universidad Nacional de General Sarmiento, Argentina. Correo electrónico: leoeiff@yahoo.com.ar

Reconocimiento - No Comercial (c) (1) (3) 
tradition. Second, it identifies a political moment of his philosophy linked to Machiavelli. Then, it highlights the reasons behind the disconnection between Merleau-Ponty's Machiavellian view of politics and the original perspective on institution. Finally, it addresses the question of whether such disconnection, which in the lectures becomes an absence, does not signal towards a different way to think politics linked to other concepts of the thought of Merleau-Ponty: Life, time and institution. These concepts were developed by him to undermine the predominance of the philosophies of reflection, which can expand new horizons regarding politics and the connection between the instituting and the instituted.

Keywords: Institution; Absence; Politics; History; Revolution; Form; Life; Time.

\section{Introducción}

$\mathrm{E}$ 1 sugerente curso merleau-pontyano sobre la Institución ${ }^{2}$, que arroja un sinnúmero de pistas para recrear el entrelazo entre vida y sentido, calibrar de otro modo la temporalidad e indagar, entre otras aristas, una posible fenomenología de la institución, delata una llamativa ausencia, que podría obviarse si no fuera porque Merleau-Ponty pensó con singular énfasis la cuestión. Tras una presentación general de la problemática, la primera parte del curso desglosa distintas formas de institución: la vida, el sentimiento, la obra, el saber, la cultura, la historia. ${ }^{3}$ Ellas son matriciales, cifras de la reflexión filosófica merleau-pontyana, condensación de sus preocupaciones recurrentes (la percepción, la conciencia, el tiempo) y de sus nuevos horizontes (la vida, el inconsciente, lo común), sobre todo, haz de pensamientos deshilachados - no del todo continuados en su obra tardía-, pero irradiantes. Por eso, los especialistas y lectores bucean en el curso de 1954-1955: porque allí algo nuevo parece irrumpir. La urdimbre de otro pensar. Sin embargo, la carencia de una reflexión sobre la institución de la política acaso ponga en entredicho la novedad filosófica del curso. En realidad, ante todo, debemos subrayar la sorpresa. MerleauPonty interrogó con fruición dicho campo de sentido; dedicó, como se sabe, libros, artículos, debates y polémicas; aún más: mientras dicta el seminario escribe Las aventuras de la dialéctica, y los préstamos son palmarios, principalmente en torno a las figuras enjambradas de temporalidad, dialéctica, historia y acción. Entonces: ¿por qué la política no merece un apartado exclusivo al lado de la vida biológica, la cultura o la historia? Además, la particular traducción de stiftung por institution parece indicar un intento de politizar el término, o al menos, como sugiere Larison, la traducción inscribe el concepto en otra tradición ajena al pensamiento estrictamente husserliano, como es el caso del pensamiento social francés ${ }^{4}$. Las resonancias políticas de la operación son notorias, también las posibilidades que abre. En suma, consideramos pertinente interrogar los motivos de la omisión, puesto que de ella acaso no solo surjan los límites de una reflexión sino, y es lo decisivo, el indicio de un camino a explorar.

2 Merleau-Ponty, La institución - la pasividad (Barcelona: Anthropos, 2012). Versión original: L'institution dans l'histoire personnelle et publique. Le problème de la passivité, le sommeil, l'insconscient, la mémoire. Notes de cours au Collège de France (1954-1955) (París: Belin, 2003)

3 El artículo aborda la primera parte del curso (L'institution dans l'histoire personnelle et publique); la segunda parte, que concibe la institución más allá de su dimensión pública, explorando los vericuetos que anudan y desanudan la subjetividad, la vida personal, la conciencia y el inconsciente, no será objeto de nuestras reflexiones puesto que, prima facie, escapan a consideraciones de índole política, al menos tal como nosotros la exploramos en este artículo.

4 Larison, "Fenomenología de la institución. Filosofía y ciencias humanas", 218. 
Como se lee en Elogio de la filosofía, la polémica de la filosofía con los dioses de la Ciudad no se resuelve con el retiro hacia el terreno seguro de la vida contemplativa o escondiéndose detrás de la vida decente de los sistemas filosóficos. La enseñanza socrática es otra. Si Lucrecio abre el libro II De rerum natura con la siguiente imagen: "Es dulce cuando sobre el vasto mar los vientos revuelven las olas, contemplar desde la tierra el penoso trabajo de otro; no porque ver a uno sufrir nos dé placer y contento, sino porque es dulce considerar de qué males te eximes" 5 - frase que puede leerse como metáfora de la filosofía ante los no filósofos condenados al imprevisible infortunio de la existencia mundana-, podemos conjeturar, en cambio, que Merleau-Ponty es el filósofo en la nave (como Spinoza según Tatián ${ }^{6}$ ), para quien filosofar supone vivir con los demás, en el medio de los otros, en relación de contigüidad con la pasiones humanas. Por eso, nuestro autor es un filósofo de lo político; y ese rasgo, antes que ningún otro, amerita rastrear las razones de una ausencia.

\section{Solapamiento}

En primer lugar, debemos conceder que el discurrir de lo político atraviesa el curso. La sensibilidad del filósofo, cuya politicidad es indudable, reabre una y otra vez la cuestión. Primero, por la propia desinencia del término institución (pública, histórica); segundo, en determinadas elucidaciones, por ejemplo: la Revolución es institución. En todas lo político irrumpe. Pero lo hace de manera superpuesta, entre otras figuras, sin recorte conceptual alguno. A diferencia de la vida biológica, la obra, la cultura, Merleau-Ponty no parece buscar asir el sentido de lo político. En rigor, sospechamos que eso está detrás porque conocemos de antemano los intereses y la perspectiva del filósofo. Sin embargo, para una mirada menos cargada el enfoque denota un solapamiento entre historia y política, en la que la segunda es vista a la luz de la primera. Es decir: el solapamiento arriesga una confusión.

Es obvio que el lugar de lo político corresponde al último tramo del seminario -La institución histórica: particularidad y universalidad-, donde se hilvana una puesta en cuestión cruzada de la filosofía de la historia y las ciencias sociales, a partir de Hegel, quien condensaba las tensiones intelectuales en la “época de posguerra", la renovación historiográfica producida por la Escuela de los Annales y los trabajos antropológicos de Lévi-Strauss. Ante las preguntas: ¿hay una historia?, y si la hay ¿cómo se anudan sus diversos estratos temporales?, Hegel responde que hay una historia, pero solo para el filósofo. LéviStrauss sugiere que hay historias - plurales, incidentales, coyunturales y azarosas-, pero su unidad solo se aprehende fuera de ella, rompiendo con lo vivido. Según Lucien Fevbre, no hay una historia, existen tiempos históricos, horizontes de historicidad. Pero el cogollo es cómo un tiempo puede penetrar en otro, cómo se abre el tiempo para que el historiador, desde otra temporalidad, lo conozca. El problema de la historia es el de su universalidad. Merleau-Ponty escudriña los límites de las respuestas dominantes: el filósofo baña de historia particular el concepto al precio de subsumir la historicidad de los acontecimientos al sistema; los científicos sociales solo calibran particularidades, diferencias históricas, mensurables vía objetivación metodológica, que ocultan su propia historicidad. Se trata del despunte de una perspectiva original que ofrece un rastreo a contrapelo de las disyunciones matriciales del pasado siglo: identidad / diferencia, agencia / estructura, etc. Por otra parte, el abordaje reenvía a la médula del curso, resumida en

5 Lucrecio, De la naturaleza, 159.

6 Tatián, Spinoza disidente, 127. 
la frase: "el tiempo es el modelo de la institución". Los debates en torno al ser de la historia, a la entidad de su discurrir inseparable del modo de su intelección, abona el terreno para la recreación radical de la noción de temporalidad.

Ahora bien, son los ejemplos antes que el rigor conceptual aquello que ensancha lo político hacia un espacio tiempo público. Merleau-Ponty atisba la noción de una transtemporalidad originaria señalando que "no es la presencia del futuro en el presente (Revolución permanente), sino institución en estado naciente; ni mímica del pasado (Guérin) ni fulguración del futuro (Trotsky)" " Guérin escribió sobre la Revolución francesa y la imaginó de modo mimético junto a la Revolución de octubre: El Zar por el Rey, los Kadetes por los Girondos, los mencheviques por los jacobinos, el proletariado peterburgués por el parisino, con una única diferencia medular: la ausencia de bolcheviques, es decir, de dirección revolucionaria. Así, en lugar de triunfar la dictadura proletaria triunfa la dictadura burguesa. Trotsky, por su parte, observa en cada suceso a lo largo del orbe, debido a su intelección del capitalismo como sistema desigual y combinado, la posibilidad latente de socialismo, es decir, de un centellante salto de etapas; también asociado a la existencia de una dirección revolucionaria férrea. Perspectivas que disuelven el tiempo puesto que lo vuelven igual a sí mismo, por eso capaz de enrollarse o desenrollarse, anticiparse. No: "el tiempo originario está a tiempo, es el tiempo que es" carácter paradigmático de las ilustraciones históricas, parece que el filósofo usa hechos y libros políticos para pensar el tiempo en su originalidad. Es cierto que es factible concebirlo de manera inversa: es la preocupación política -el destino de la Revolución-, el descubrimiento de sus encerronas, aquello que impulsa la renovación filosófica que comienza a insinuarse. Sea como casos ejemplares o como instigación, lo político y la política, en el curso sobre la Institución, es un insumo que no merece un tratamiento singular. La conjetura de su solapamiento con la historia es plausible puesto que conocemos la relación de Merleau-Ponty con el marxismo. Lo político es la Revolución: la Historia. El trabajo filosófico con la política va a consistir en extirpar las mayúsculas -secularizar palabras magnas- sin clausurar el horizonte de transformaciones que abrió la posibilidad de realizar la filosofía.

Cabe indagar, entonces, por qué Merleau-Ponty aloja lo político en el campo de la historia, por qué para preguntar por el ser de la política debe preguntar por la historia o, finalmente, por qué los ejemplos políticos (con sus nombres resonantes) corresponden a casos históricos en el sentido conceptual del término.

\section{Hegel y Marx como causa}

Hannah Arendt afirmó que, en general, cuando los modernos escriben sobre política en verdad redactan una nueva filosofía de la historia. ${ }^{9}$ El cambio conceptual en la noción de historia analizado sesudamente por Koselleck ${ }^{10}$, y consagrado con las revoluciones modernas, volvió inextricables política e historia. La eficacia teórica y política del marxismo no hizo más que confirmarlo. La política pierde su especificidad

7 Merleau-Ponty, La institución, 6.

8 Merleau-Ponty, La institución, 6.

9 Arendt, De la historia a la acción, 65.

10 Koselleck, Futuro pasado (Barcelona: Paidós, 1993). 
a manos de la historia y la sociedad. Por contraste pueden comprenderse la serie de interrogaciones alrededor del concepto de lo político, o más directamente: ¿qué es la política? Una franja significativa del pensar contemporáneo indaga la singularidad política puesto que ella perdió inteligibilidad al extenderse su uso y aplicarse para iluminar situaciones, espacios, sucesos, que antes (ejemplarmente la polis y la república clásica o la época dorada de la soberanía estatal bajo el absolutismo) se consideraban como no políticos. Algo similar ocurre con el retorno a Maquiavelo: el momento maquiaveliano como momento político. No voy a abundar en una conocida historia interna de la teoría, punto nodal del pensar filosóficopolítico del pasado siglo, ligada, digamos, a la querella por la autonomía de lo político. Disputa, por cierto, anudada a la validez heurística del marxismo. La obra merleau-pontyana es parte de esta historia conceptual, sin embargo, el dictum arendtiano parece caberle.

Merleau-Ponty piensa la política en relación estrecha con la filosofía hegeliana de la historia y la praxis revolucionaria marxiana. En el interior de ese lenguaje produce torsiones, aperturas, pero también cristaliza sentidos. Por ejemplo: la ausencia de una reflexión en torno a la forma de lo político, el régimen de gobierno o la dimensión simbólica de la ley en cuanto estructurante del campo de lo social. Por otra parte, Marx es leído en ruptura con Hegel, aunque con la mácula convencional de la inversión, pero en relación de continuidad con el marxismo: Lenin, Trotsky, Lukács, y la realidad soviética. Hay menos una reflexividad sobre lo específicamente marxiano, capaz de renovar la filosofía, la historia y la política, que una puesta en juego de su validez histórico-concreta. Merleau-Ponty analiza el socialismo como narración teórica y sucesos concretos antes que las consecuencias teórico-políticas que se derivan de la obra de Marx. La primera ausencia reflexiva acaso explique la originalidad de Lefort, cuyo pensar se organiza a partir de los hilos sueltos de la obra merleau-pontyana. En el prefacio a la segunda edición de Humanismo y Terror, Lefort sugiere que el confuso abigarramiento entre política e historia (una historia concebida como proceso, devenir y salto a lo absoluto, claro está), impide calibrar la novedad de la forma política soviética -más adelante: la distinción entre la experiencia del totalitarismo y la experiencia de la democracia- cuya consecuencia supone un menoscabo de los alcances de la represión (el universo concentracionario) y un vano sembrar expectativas de reforma. El enfoque respecto a Marx y el marxismo, que Merleau-Ponty comparte, entre otros, con Sartre, anuncia el impacto novedoso de la empresa althusseriana: retornar a Marx por un lado y postular la especificidad, movilizando la noción de autonomía relativa, de las prácticas por el otro.

En suma, existirían tres causas, imputables in toto a la relación con Hegel y Marx, que pincelan las razones de la ausencia: la disyunción entre una fenomenología de la conciencia y una fenomenología de la acción, la imposibilidad de la dialéctica para asir lo político y las fronteras de lo posible dentro del campo intelectual francés entre 1945-1960. En primer lugar, a pesar de que el filósofo hunde la conciencia en la percepción, la política parece ser un capítulo de la odisea de la conciencia hegeliana. De allí el singular interés por la problemática de la conciencia de clase o el Partido como haz de prácticas y condensación de la conciencia revolucionaria. $\mathrm{O}$, a fin de cuentas, el destaque del joven Marx. Inscribir la política en dicha dimensión abre a la cuestión de la alienación, el fetichismo o la imaginación. La política anudada a un juego especular cuya médula es la figura de la negación. Sabemos que Merleau-Ponty puso progresiva, pero radicalmente, en cuestión la filosofía de la conciencia -y sus sucedáneos: la negación, determinación y autoconciencia-, aunque, también sabemos, que tal movimiento lo arrojo menos hacia la acción en común, la pluralidad humana como factum de lo político, que, a una torsión balbuceante de la figura de la praxis, indagada, ahora, como carne. Merleau-Ponty retoma la praxis extirpándola de su argamasa hegeliana a fin de inocularla como carne del mundo. Como sea, y dicho en términos arendtianos, el pensamiento merleau-pontyano adolece de una fenomenología de la acción que le hubiera permitido 
ingresar al mundo contingente de la vida activa. La práctica política indaga la paradójicamente potente fragilidad de lo común antes que las desdichadas tribulaciones de la conciencia, tironeada, cuando sale de viaje por la historia, entre lo mismo y lo otro.

En segundo lugar, la dialéctica entre lo mismo y lo otro, que según un conocido ensayo ${ }^{11}$ condensa un ciclo completo de la filosofía francesa, aunque enraizada en los meandros de la existencia, remite a Hegel, a la lógica del concepto, sea para continuarlo, invertirlo o execrarlo. La dialéctica es la figura que inscribe la acción política en una zona dinámica, en el imaginario de la revolución, o en el devenir de la potencia al poder. Reside en el cruce candente de los saberes del siglo, cuyo uso político no encuentra parangón filosófico. Merleau-Ponty no dejo de explorar la potencia heurística de la dialéctica, tensando sus sentidos hasta los sinsentidos, iluminando sus paradojas, extremando la fuerza de lo negativo sin la consolación de la superación, es decir, convirtiendo la negación en diferencia. Dialéctica encarnada o hiperdialéctica. Sin embargo, su pensar político no parece haber rebasado dicho horizonte, tropezando a menudo con la confusión aludida entre política e historia. En el campo concreto del análisis histórico y político los juegos dialécticos produjeron estragos. Por ejemplo: la relativización de la diferencia entre el bien y el mal para la conciencia práctica o la tesis según la cual las acciones son solo juzgables en el porvenir abierto de la Revolución. El enjambre dialéctico anestesiaba el juicio crítico (la reflexividad) y el salto del sujeto al tren en marcha de la historia (compromiso) lo ponía a merced del Poder, puesto que el Dios escondido de la Historia había designado representantes en la tierra encargados de preparar o administrar el porvenir. Así, lo político se extravía entre audacias dialécticas, que, sin embargo, participaba de la koiné que escindía, de modo escolástico, al marxismo entre ortodoxia y heterodoxia.

En tercer lugar, vale decir que los dos puntos anteriores admiten una explicación histórico-contextual que acaso matice las desavenencias teóricas. Parafraseando a Sartre: el marxismo era el horizonte insuperable de la época. Los faros, infinitamente distinguibles, pero en el fondo indiscernibles, de la Revolución y el país de los soviets, por un lado, y la existencia de un partido comunista de masas en Francia, cuya raigambre obrera (incluso "obrerista") era palmaria, por el otro, constituían un magma de sentido, plagado de disyunciones y, al mismo tiempo, cerrado sobre sí mismo. Merleau-Ponty aguijonea las cristalizaciones pujando por un marxismo sin ilusiones primero y por la revisión sesuda de una experiencia que tentó el devenir práctico de la teoría después; recusando, siempre, la "idea de una purificación absoluta de la historia, de un régimen sin inercia, sin azar y sin riesgos" ${ }^{12}$. No obstante, a pesar de su plasticidad, el horizonte merleau-pontyano cabe en los nodos de la guerra, la revolución, la descolonización, que, en el plano filosófico-político signan el desplazamiento de la historia como singular colectivo hacia el sujeto como conciencia trágica. Humanismo y terror es legible en esa clave: la crítica de la filosofía de la historia en cuanto singular colectivo pleno de sentido y la figuración subjetiva de una práctica política sin certezas que solo accede de modo frágil, trágico, a la historia. Como una apuesta, o aventura, que politiza la resonancia pascaliana del dictum. Contexto que reactualizaba el problema de la legitimidad de la violencia y obligaba a leer, y discutir intensamente, los legados de Hegel y Marx. La fidelidad amistosa e intelectual, que incluye polémicas relevantes y contrapuntos filosóficos agudos, de Merleau-Ponty para con Sartre puede comprenderse dentro de ese régimen de pasiones. La correa que liga a Hegel con Marx, a estos con Lenin y Trotsky, a la URSS como realidad lacerante pero tangible y

11 Descombes, Lo mismo y lo otro (Madrid: Cátedra, 1982).

12 Merleau-Ponty, Las aventuras de la dialéctica, 9. 
posible con la clase obrera que vota masivamente por el PCF, al marxismo de Sartre con el de Maurice Thorez, organiza un calidoscopio que reflecta el contexto intelectual en su radical historicidad.

En suma, que la dialéctica sea una aventura antes que un conjunto de leyes generales y determinantes es sugerente solo dentro de una zona de intelección signada por el enjambre entre historia y política, y validado por el porvenir de la Revolución. Si ella caduca, y el último Merleau-Ponty no dejaba de intuir signos de esa caducidad, se impone el divorcio con la comunidad marxiana y la consecuente búsqueda de lo político por fuera, y contra, la marcha del espíritu negativo. En otros términos: Lefort completa a Merleau-Ponty. Lefort concluye la apertura insinuada por la obra de pensamiento merleau-pontyana, pero no concluida puesto que estaba saturada de causalidad hegeliano-marxiana, consagrando la singularidad de lo político cuya experiencia ya no es habitable por el sujeto revolucionario trágicamente concebido sino por la democracia como autoinstitución permanente -conflictiva, sin certezas ni garantías- de la sociedad.

\section{Momento político}

El apartado anterior, que condensa un conjunto posible de explicaciones críticas respecto a la ausencia a lo largo de la obra de Merleau-Ponty de una pregunta al estilo arendtiano: ¿qué es la política?, puede ser refutado sugiriendo que la insistencia merleau-pontyana con Hegel y Marx no obturo necesariamente su comprensión de lo político. Acaso sea lo contrario. Creemos haberlo demostrado en otra oportunidad ${ }^{13}$. El pensar político de Merleau-Ponty forma parte del extenso capitulo maquiaveliano que atravesó el pasado siglo: la política como efecto de una ontología signada por la contingencia y el conflicto. El filósofo en la Ciudad, en el navío con los otros, no fue indiferente al agudo florentino, quien metaforiza, al comienzo de sus Discursos sobre Tito Livio, contra las seguridades de la tradicional vida contemplativa: "Aunque por la naturaleza envidiosa de los hombres la tarea de buscar nuevos métodos y recursos haya sido siempre tan peligrosa como buscar aguas y tierras ignotas, porque todos están dispuestos a denostar que a loar las acciones ajenas, sin embargo (...) me he decidido a entrar por un camino que, como no ha sido aún recorrido por nadie, me costará muchas fatigas y dificultades"14. En el barco que se bambolea entre la virtù y la fortuna, y como parte del momento maquiaveliano, Merleau-Ponty piensa lo común: la vie à plusieurs.

La cuestión por indagar es: ¿cómo piensa lo político? Quizás allí resida la clave para cotejar las razones de su ausencia en el curso sobre la Institución. ${ }^{15}$

En primer lugar: lo político como acción. El enfoque del filósofo francés privilegia la acción; la acción como inauguración de un espacio-otro, develamiento que es, al mismo tiempo, un proceso inacabado. La acción es percepción. Así, supone una revalorización del mundo de la doxa, de la experiencia

13 En lo que sigue vamos a reponer las tesis principales y conclusiones de nuestra investigación sobre Merleau-Ponty, filósofo de lo político, desde nuestras preocupaciones actuales. Remitimos al libro para conocer el desarrollo sesudo de la argumentación.

14 Maquiavelo, Discursos sobre la primera década de Tito Livio, 25.

15 Los textos medulares para pesquisar el sentido de lo político en Merleau-Ponty son: "Lectura de Montaigne", "Nota sobre Maquiavelo", "Prefacio a Humanismo y terror". 
sensible: la política discurre en el mundo de la apariencia, entendida como espacio de aparición. Se trata de una fenomenología de lo político, que, a pesar de su tensión hacia la conciencia y lo imaginario, permanece amarrada a lo público como resplandor de la acción. La figura reenvía a la noción griega de praxis, y a su reactualización moderna bajo la filosofía de la praxis. La acción es plural y conflictiva; su fragilidad proviene de ambas modulaciones, cuya grava es histórica y social. Merleau-Ponty concibe lo histórico-social como el lugar, público, donde la acción puede enraizarse, ganar espesor y ensanchar sus posibilidades. Lo histórico-social, entonces, pulido del ademán marxista, es decir, realizada la crítica de la "metapolítica marxiana", para usar una expresión de Rancière ${ }^{16}$, no supone una desertificación de la política; al contrario, es fulgor y potenciación.

En segundo lugar, la estructura de la acción está constituida por la contingencia y el conflicto. La vie à plusieurs entraña un maleficio: la imposibilidad de hallar un buen orden, estable y armónico. Lo fundamental en Maquiavelo, sugiere Merleau-Ponty en su decisiva lectura, es el descubrimiento de que la política transcurre y se define en la vida concreta de los pueblos y no en el cielo abstracto de las buenas intenciones. Lo concreto en política es la contingencia. El conflicto, el antagonismo y la lucha residen en el origen (plural) de lo social, porque la indeterminación es el índice de la vida común. El conflicto emerge también de la singular interacción entre los hombres: la opinión. La radicalidad maquiaveliana, frente a la tradición de la filosofía política, reside en la transformación de la apariencia en la verdad de la política. El rodeo por Maquiavelo permitía reconsiderar, desde las dimensiones de la contingencia y el conflicto, el problema político de la legitimidad de la Revolución, es decir, de un ejercicio distintivo de la violencia. Eludiendo el cobijo dogmático de la metafísica histórica, la cuestión irrumpía descarnada: "el mundo humano es un sistema abierto e inacabado y la misma contingencia fundamental que lo amenaza de discordancia lo sustrae también a la fatalidad del desorden y prohíbe desesperar de él”. ${ }^{17}$

Las dos precisiones en torno a lo político no podían omitir el hiato que se abría con el marxismo, que siempre fue pensado por nuestro autor como paradigma del sentido. O bien se optaba por la tesis de la ruptura con el marxismo ${ }^{18}$, o bien se exploraba un camino de renovación, profundización y convergencia. Fue el nuestro. 1) Maquiavelo y Marx, 2) entrelazamiento entre el momento maquiaveliano y la carne de la historia, 3) aventura democrática y crítica de la dominación. El primero inscribía a nuestro autor en la saga de la "izquierda maquiaveliana" (junto a Gramsci, Lefort, Althusser, Negri, etc.), cuyo rasgo es la exploración fructífera de la imbricación de lo político y lo histórico-social, antes que el énfasis en el corte o la autonomía de sus hebras significativas. El segundo descubre la reversibilidad de lo político y lo histórico-social: la carne de lo político acoge el discurrir histórico y la carne de la historia adquiere visibilidad significativa en la afinidad ontológica entre la conflictividad contingente y lo político. Así, la gramática de la acción se traza en un campo rugoso y sedimentado, un campo minado que, sin aplacar su radical indeterminación, lo ancla a través de la figura del entrelazamiento. Finalmente, si bien la concepción merleau-pontyana podía vincularse a la perspectiva de la revolución democrática (de Tocqueville a Lefort), su distanciamiento del comunismo real no aflojaba su crítica al capitalismo como régimen social. "el anticapitalismo sigue siendo una brújula"19 . De esta forma, y en la senda abierta

16 Rancière, El desacuerdo, 111.

17 Merleau-Ponty, Humanismo y terror, 309.

18 Lefort, Sur une colonne absente; Melançon, Merleau-Ponty et la politique; Peillon, La tradition de l'esprit. Itinéraire de Merleau-Ponty; Revault d'Allons, Merleau-Ponty, la chair du politique.

19 Corcuff, Merleau-Ponty ou l'analyse politique au défi de l'inquiétude machiavélienne, 214. 
por Abensour ${ }^{20}$, el redescubrimiento de lo político profundiza la crítica de la dominación, es decir, el contraste entre capitalismo y democracia.

Ahora bien, mis argumentos, válidos para iluminar la originalidad y relevancia de lo político en la obra de Merleau-Ponty, iban demasiado lejos, tendían a generalizarse sin mayor precaución, en al menos dos aspectos: por un lado, la fidelidad a la hipótesis del retorno de lo político confiaba en que la primacía de la acción alcanzaba para fundar la institución de lo político; por otro lado, el estricto recorte de una problemática política -que, a pesar de declarar la solidaridad entre filosofía y política las escindía de hecho- soslayaba la crucial diagramación del pasaje entre una fenomenología de la percepción hacia una ontología de lo percibido, cuya transito exigía una reconsideración de lo viviente. Así, podemos conjeturar que se nos escabulló, entre la hojarasca del momento maquiaveliano, el marxismo y la revolución, el sutil desplazamiento del sentido de lo político a la vida política.

\section{Vida y política}

La tradición filosófico-política opera a través de un recorte y una distinción. ¿Cuáles es el punto donde la vida se torna humana, es decir, inconmensurable respecto a la vida en general? ¿Cómo se diferencian la vida filosófica y la vida política? Conocemos la medular respuesta griega: logos y praxis. Ambas timbran el umbral, mediante el pasaje, entre zoe y bios. Las consecuencias fueron decisivas: un nítido sistema de oposición entre la verdad y lo verosímil, conocimiento y juicio, necesidad y libertad, para tentar solo algunas, las políticamente más relevantes (Merleau-Ponty explora otras: lo interno y lo externo, lo innato y lo adquirido, lo orgánico y lo aprendido, lo individual y lo social, lo privado y lo público). En el consagrado esquema de inteligibilidad la política cobra aristotélica significación en el triángulo del sentido, la acción y la producción, cuya temporalidad cifra un movimiento prospectivo. Lo político en Merleau-Ponty sigue, prima facie, esta línea clásica a través de una comprensión fenomenológica del sentido, una indagación maquiaveliana de la acción y un rastreo marxiano y estético de la producción, tonificado por una temporalidad regida por la conciencia. Por eso, siempre fue posible establecer bosquejos comparativos con Arendt, señalando diferencias y semejanzas.

Ahora bien, cualquiera sean las variaciones del retorno de lo político existen, al menos, dos problemas irresolubles: la nunca zanjada polaridad entre lo instituyente y lo instituido y la imposibilidad de hallar una acción política autónoma en el mundo contemporáneo -el reino de la sociedad del espectáculo-, es decir, desligada de intereses, estrategias y finalidades. El divorcio abismal entre verdad y política, que extrema la tradicional malquerencia entre filosofía y retórica, y no solo el crepúsculo de la Revolución (la drástica antinomia entre la revolución soviética y el régimen soviético, para mentar un ejemplo caro a nuestro autor), arrincona las reflexiones en el conteo de pérdidas y retrocesos (la "desdemocratización" es una de las últimas ante acontecimientos recientes) o en venturosas fulguraciones (los movimientos que irrumpen por doquier) que indefectiblemente van disipando su fragor hasta situarnos en la desdicha anterior. Asistimos, hace décadas ya, a la explosión del triángulo entre sentido, acción y producción. Hay quienes, de modo nietzscheano, postularon consideraciones impolíticas ${ }^{21}$, otros indagaron la vida

20 Abensour, Pour une philosophie politique critique.

21 Esposito, Categorías de lo impolítico. 
filosófica como práctica terapéutica, intentando superar la contraposición entre vida contemplativa y vida activa, y la llamaron, por ejemplo, "ejercicios espirituales"22 o "escrituras de s" cuya cifra politiza - ¿o moraliza o estetiza? - la existencia. En cualquier caso, el crujir del paradigma del sentido (para nosotros: el sentido de lo político) abrió la exploración de las formas-de-vida. Pensamos, en fin, que el curso merleau-pontyano puede ahondar el surco puesto que, por un lado, la institución es forma de vida y, por el otro, su caja de resonancia recrea radicalmente los emblemas de la acción, el sentido y la historia. Veamos, brevemente, cómo; para luego, retomando la cuestión ausente, finalizar.

Dos formulaciones orientan el seminario: la figura de la institución como remedio para las dificultades de las filosofías de la conciencia y el tiempo como modelo de la institución. Mariana Larison ${ }^{24}$ viene indagando la originalidad merleau-pontyana en torno al abordaje del tiempo a través de una reconstrucción de los principales hitos alrededor del decisivo concepto que supo legar la tradición filosófica. El abandono del paradigma de la conciencia implica la puesta en cuestión de la estructura que la forja, y el concepto de tiempo ligado a las figuras del movimiento, la inmanencia y la interioridad, desgajado del espacio y la sensibilidad, o como forma que hace posible lo sensible, es crucial andamiaje ontológico. MerleauPonty explora otras imágenes: simultaneidad, transtemporalidad, advenimiento, cuasi-eternidad. Así, frente a los jalones de la tradición que concibieron el tiempo como sucesión (Aristóteles), interioridad (de Agustín a Husserl), opuesto a cualquier referencia espacial (de Kant a Bergson), mundano, pero radicalmente privado (Heidegger), se yergue el intento de renovar su interrogación impulsando una temporalidad sensible, material y originariamente pública. Vale preguntar, entonces, por sus consecuencias políticas. Esto es: ¿la fragua de un nuevo triángulo entre institución, tiempo y vida puede cobijar lo político? Nosotros siempre consideramos que Merleau-Ponty situaba la política fuera del paradigma de la conciencia, sea por su filiación con la historicidad marxista sea por el momento maquiaveliano como momento político; pero, sin embargo, como bien (nos) señaló Claudio Cormick ${ }^{25}$ la atribución de responsabilidad política a tal o cual actor, a pesar del esfuerzo por deslindar lo político de lo jurídico, implica, antes que excluye, la dimensión de la conciencia. Tal el caso de Humanismo y terror, y otros ensayos merleau-pontyanos. De algún modo la conciencia insistía, volvía a irrumpir. Lo hacía menos por cuestiones epistemológicas que por la problemática del soporte, o polo aglutinante, de la historicidad de la acción. La conciencia era iluminación ontológica para el despliegue de la acción histórica. Ahora bien, si pensamos en la institución de la vida antes que, en la conciencia constituyente, en la simultaneidad antes que, en el rasgo prospectivo del tiempo, ¿podemos percibir la vida política fuera del sentido que ofrece la inteligibilidad de la razón práctica?

Sondeamos un terreno cenagoso, que, no obstante, nos aproxima a las motivaciones profundas de la ausencia. Dos posibles inferencias. La primera ligada a un desfasaje entre las intuiciones ontológicas y una concepción de lo político aún demasiado anclada en la tradición, y en las querellas perentorias que esbozaba el marxismo, cuyo acotamiento cabe aguardar conforme se asiente la nueva ontología, aunque sabemos que eso nunca acabó de suceder, antes bien, la divergencia se fue ahondando. La segunda es más inquietante: tras el gran intento de Las aventuras de la dialéctica que anunciaba nuevas reflexiones

22 Hadot, Ejercicios espirituales y filosofía antigua.

23 Foucault, L'écriture de soi.

24 Larison, Merleau-Ponty y la contemporaneidad del tiempo: el problema de los tiempos. (inédito).

25 Cormick, Una vez sobre la noción de responsabilidad histórica en Humanismo y terror. 
políticas, sucede un progresivo oscurecimiento de lo político registrado, por ejemplo, en el prólogo de Signos. Por supuesto no debemos interpretarlo en el sentido vulgar de una elección de la filosofía contra el compromiso; sin embargo, la ausencia azuza la siguiente interrogación: ¿la forma política encuentra su estructura de potenciación solamente en los campos de la práctica, la conciencia emancipada y la historicidad progresiva? De lo contrario, la obturación de ese campo de inteligibilidad mina nuestra capacidad de asir la distinción y el vigor de lo político. Hubo intentos, sin duda, que indagan zonas desconocidas, el revés de trama de la modernidad política, pero, al menos hasta ahora, su relevancia filosófica difícilmente pueda cuajar con figuras de lo real. El sonsonete de la ausencia es agudo juicio sobre el vaciamiento del sentido de lo político a mediados del pasado siglo, cuyo efecto es menos una herencia sin testamento que el completo borramiento de una experiencia. ¿Pero pueden conformarnos estas razones? La politicidad del término institución y la publicidad originaria del tiempo acaso arrojen otras pistas, aunque ya no para indicar móviles de la omisión sino para continuar pensando políticamente en un momento de honda descomposición: de los saberes, la política realizada o realizable, de lo simbólico, del mundo.

El tema que se abre es vasto y harto problemático. Entonces, para concluir tres esbozos o caminos plausibles a partir de, pero sobre todo más allá, de Merleau-Ponty.

Despojada del señorío de la conciencia la vida es materia que pierde su forma intangible. Es vida personal para un viviente, es decir, recorte del continuum vitae a partir de la impronta, la lengua, el amor, el saber o la cultura, pero encarnada: forma de vida. De este modo, la asociación entre praxis y política, nodo de la vida práctica (bíos), su distinción respecto a la vida contemplativa, y su ligazón a la libertad, puede horadarse, aunque menos porque desde los albores es biopolítica que por su rasgo institucional antes que fundacional. La vida política es institución ("la revolución es institución, dice Merleau-Ponty), como la praxis es carne, porque es acontecimiento y matriz, superación de los polos de la libertad y la necesidad. En suma, retomando a Maurice Hauriou, se trata de indagar el "vitalismo de la institución"26. Así como la vida se torna personal, sin necesidad de recurrir a la conciencia como ente privilegiado de vivencias, a través de una serie de operaciones, cabe rastrear cómo la política se vuelve institución o cómo la institución es vida política, sin privilegiar ningún lugar, intervención, mecanismo o foco de irradiación.

En segundo lugar, si Arendt pensó la revolución como fundación de la libertad, cuya modernidad implica su trabazón con la experiencia de lo nuevo ${ }^{27}$, producir una desavenencia entre fundación e institución (cuya cercanía teórico-política presupone un considerable esfuerzo conceptual) exige, para comenzar, conservar los dos extremos polares que conforman el término institución: lo instituyente y lo instituido. Es decir, no ceder ni a la contraposición entre libertad y ley ni a la síntesis republicana; por el contrario, abrir un campo de experiencia que disuelva la tensión que habita en los énfasis contrastantes o en los esquemas precarios de equilibrio -dicha tirantez recorre como un eje vertebrador al pensamiento político moderno, en cada una de sus modulaciones discursivas, simbólicas e ideológicas, hasta el extremo de ser una de las explicaciones de su crisis abismal-, una dinámica, una dimensión que es ramillete antes que polarización. De algún modo, la institución política es cruce entre la vida y el territorio -modo de

26 Hauriou, La teoría de la institución y de la fundación, 54.

27 Arendt, Sobre la revolución, 37. 
enjambrar tiempo y espacio, que la tradición contrapuso de infinitas maneras-, entrelazamiento que, por otra parte, se sustrae al contrapunto entre potentia y potestas.

Para que lo anterior siquiera comience a ser plausible es medular concebir el tiempo fuera de la gramática de la subjetivación. Más allá de cualquier telos práctico, cuyo sustrato rige los criterios de validez para discernir tipologías de acción, y del ajuar post-fundacional que retoma la maquiaveliana contingencia, pero no puede más que seguir deconstruyendo los aspectos disonantes de la política y las instituciones. El tiempo como modelo de la institución supone la conservación de su carácter eminentemente público -à plusieurs - y el destilar los rasgos prospectivos que entraña la pregunta por el sujeto de la acción. No hay retrasos y ni anticipaciones: el tiempo es. Su ser es simultaneidad, como la estofa que macera la figura de la institución.

Resta interrogar con qué elementos es asequible aún la verdad de la política -y si lo sigue siendo, tal la razón cabal de la ausencia- una vez deshilachadas sus modulaciones consagradas: revolución, ley, hegemonía, praxis, telos histórico, democracia. Postulamos institución, sin duda, pero debemos cuajarla en el conjunto de acontecimientos de una experiencia (política) que la dotan de dimensiones durables, continuidad pensable. O a la inversa: después del fin y del reinado inmoderado del sintagma "post", solo cabe tentar lo político en harapos.

\section{Bibliografía}

Abensour, Miguel. Pour une philosophie politique critique. París: Sens \& Tonka, 2009.

Arendt, Hannah. Sobre la revolución. Madrid: Alianza, 1988.

Arendt, Hannah. De la historia a la acción. Buenos Aires: Paidós, 2005.

Corcuff, Philippe. "Merleau-Ponty ou l'analyse politique au défi de l'inquiétude machiavélienne". Les Études philosophiques, no.57 (2002): 203-217.

Cormick, Claudio. "Una vez más sobre la noción de responsabilidad histórica en Humanismo y terror". Areté, vol. XXVIII, no. 2 (2016): 305-335.

Descombes, Vincent. Lo mismo y lo otro. Cuarenta y cinco años de filosofía francesa (1933-1978). Madrid: Cátedra, 1982.

Eiff, Leonardo. Merleau-Ponty, filósofo de lo político. Los polvorines: colección humanidades Ed. UNGS, 2014.

Esposito, Roberto. Categorías de lo impolítico. Buenos Aires: Katz, 2006.

Foucault, Michel. "L'écriture de soi", Corps écrit, no.3 (1983): 5-17.

Foucault, Michel. "El uso de los placeres", Historia de la sexualidad II. Buenos Aires: Siglo XXI, 1987.

Hadot, Pierre. Ejercicios espirituales y filosofía antigua. Madrid: Siruela, 2006.

Hauriou, Maurice. La teoría de la institución y la fundación. Buenos Aires: Abeledo-Perrot, 1968.

Koselleck, Reinhart. Futuro Pasado. Para una semántica de los tiempos históricos. Barcelona: Paidós, 1993.

Larison, Mariana. "Fenomenología de la institución, entre filosofía y ciencias humanos: la vida, el tiempo y lo común". Devenires, no. 19 (2018): 217-235.

Lefort, Claude. Sur une colonne absente, écrits autour de Merleau-Ponty. París: Gallimard, 1978.

Lefort, Claude. Essais sur le politique. París: Seuil, 1986.

Lucrecio. De renum natura / De la naturaleza. Barcelona: Bosch, 1993.

Maquiavelo, Nicolás. Discurso sobre la primera década de Tito Livio. Madrid: Alianza, 1987.

Melançon, Jerôme. Merleau-Ponty et la politique: aux marges de la philosophie. Thèse de Doctorat, Diderot (París 7), París. 2008.

Merleau-Ponty, Maurice. Humanisme et terreur. París: Gallimard, 1980. 
Merleau-Ponty, M., Les aventures de la dialectique. París: Gallimard, 1955.

Merleau-Ponty, M., Signes. París. Gallimard, 1960.

Merleau-Ponty, M., Éloge de la philosophie. París: Gallimard, 1953.

Merleau-Ponty, M., L'institution dans L'histoire personelle. Le problème de la passivité le sommeil, l'inconscient, la mémoire. Notes de cours au Collège de France. París: Belin: 2003. (Versión castellana: La institución - la pasividad. Notas de curso en el Collège de France (1954-1955). Barcelona: Anthropos, 2012).

Peillon, Vincent. La tradition de l'esprit. Itinéraire de Merleau-Ponty. París: Grasset, 1994.

Plot, Martín. La carne de lo social. Buenos Aires: Prometeo, 2008.

Rancière, Jacques. El desacuerdo. Política y filosofía. Buenos Aires: Nueva Visión, 1996.

Revault d'Allons, Myriam. Merleau-Ponty, la chair du politique. París: Michalon, 2001.

Tatián, Diego. Spinoza disidente. Buenos Aires: Tinta Limón, 2019. 